\title{
Internalisasi Nilai-Nilai Religius Serial Film Nusa dan Rara dalam Pembentukan Karakter pada Anak Usia Dini
}

\author{
Mohammad Rindu Fajar Islamy ${ }^{凶}$ \\ Departemen Pendidikan Umum, Universitas Pendidikan Indonesia \\ DOI: $10.31004 /$ obsesi.v6i4.1704
}

\begin{abstract}
Abstrak
Penelitian ini bertujuan mengeksplorasi dinamika internalisasi nilai-nilai religious yang terkandung dalam serial kartun Nusa dan Rara dalam pembentukan karakter anak usia dini. Menanggapi komentar adanya unsur penanaman nilai radikal, studi ini berupaya meluruskan pandangan keliru tersebut melalui opini masyarakat pada tataran realitas. Pendidikan anak merupakan waktu tepat untuk membangun karakter mereka sedini mungkin, sehingga diharapkan dimasa yang akan datang, ia dapat menjadi seorang siswa berkarakter. Studi ini menggunakan pendekatan kualitatif, data penelitian diambil dari para sepuluh informan orang tua melalui observasi, interview, dan dokumentasi. Wawancara dilakukan secara semi terstruktur untuk menjawab tiga belas instrument. Data kemudian dianalisis menggunakan Teori Miles dan Huberman. Hasil penelitian menunjukkan bahwa mayoritas informan sepakat, serial ini baik untuk dikonsumsi oleh anak. Karakter yang dibangun dari serial ini diantaranya berbakti kepada orang tua, taat beribadah, gemar menolong orang lain, belajar giat, dan yang lainnya. Riset ini menolak tuduhan film ini mengandung unsur radikal.
\end{abstract}

Kata kunci: pendidikan karakter; islam, anak; nusa dan rara; radikal.

\begin{abstract}
This study explores the dynamics of internalizing religious values in the Nusa and Rara cartoon series in the formation of early childhood characters. There is no comment on the inculcation of radical values, and this study attempts to discuss this erroneous view through public opinion at the level of reality. Children's education is the right time to build their character as early as possible, so it is hoped that they can become character students in the future. This study uses an approach, and research data is taken from ten parent informants through observation, interviews, and documentation. Interviews were conducted in a semistructured manner to answer thirteen instruments. The data were then analysed using Miles and Huberman's Theory. The results of other studies show that inform ordering, this series is suitable for consumption by children. The characters built from this series include filial piety, parents, obedient to worship, likes to help others, study hard, and this research rejects the accusation that the film contains non-radical content.
\end{abstract}

Keywords: character education; islam; children; nusa and rara; radical

Copyright (c) 2022 Mohammad Rindu Fajar Islamy

$\triangle$ Corresponding author:

Email Address : fajarislam2000@upi.edu (Bandung, Indonesia)

Received 31 July 2021, Accepted 31 August 2021, Published 28 February 2022 


\section{PENDAHULUAN}

Dalam dua dekade terakhir, seiring dengan adanya trend peningkatan aksi-aksi radikal, aksi-aksi terror yang dilakukan oleh kelompok-kelompok ekstrem seperti ISIS, AlQaeda, para cendekiawan muslim maupun non muslim berupaya untuk mempelajari serta mengeksplorasi bagaimanakah koneksitas gerakan-gerakan ekstrem tersebut dengan nilainilai ajaran agama Islam (Kurzman, 2019; Yusof et al., 2010; Yusoff, 2010; Zamboni et al., 2009). Bahkan dalam studi riset yang dilakukan oleh John Turner, secara global jumlah orang yang bergabung ke dalam kelompok ISIS disinyalir meningkat dengan jumlah 40.000 orang dimana sekitar 15\% berasal dari negara-negara Eropa Barat seperti Prancis, Jerman, Inggris, dan Belgia (Turner, 2020). Lebih jauh, menurut Turner, serangan terror terhadap anti muslim di Perancis meningkat $500 \%$ yang mana Sebagian besar diarahkan ke masjid-mesjid disana. Disaat yang bersamaan, sarjana Indonesia Suyanto menemukan fakta bahwa Gerakan radikal bermula dari penyusupan ideologi-ideologi radikalisme kepada generasi-generasi muda yang kurang pemahamannya terhadap agama (Suyanto et al., 2019). Dari data statistic diatas, mengurai factor-faktor apa sajakah yang menjadi pendorong Tindakan terror dan radikal mulai dikaji oleh para ilmuwan nasional hingga internasional mulai dari factor politik, ekonomi, pendikan, hingga kultur dan sosial masyarakat (Saunders, 2012; Schofield, 2004; Soliman et al., 2016; Varouxakis, 2004; Yang et al., 2014). Apapun hasilnya, tanggapan bahwa Gerakan ekstrem tersebut sengaja dituduhkan kepada ajaran Islam, tentunya hal ini tidak benar. Menurut Sayyid Muhammad bin Alawi Al-Maliki seorang ulama internasional kontemporer dalam karya-karyanya menolak keras tuduhan tersebut, bahkan dengan tegas menyatakan bahwa Islam adalah agama menjunjung toleransi, memerintahkan kepada menghormati orang lain, agama damai dan kasih sayang (Al-Mālikī, 1993, 2003, 2004). Sejalan dengan pemikiran Sayyid Muhammad bin Alawi, Syeikh Yusuf Al-Qardhawi memperkuat argumentasi bahwa Islam adalah agama yang moderat, agama yang dibangun atas prinsip keseimbangan dalam segala aspek kehidupan baik duniawi maupun ukhrowi (Al-Qardhawi, 1990, 1993, 2008). Diskusi ini sengaja penulis tampilkan pada riset ini sebagai satu bahan kajian yang dapat dimungkinkan adanya keterkaitan percaturan perang pemikiran tersebut dengan tuduhan bahwa serial Nusa dan Rara mengandung unsur radikalisme.

Berpindah dari diskusi dan opini terkait wacana radikalisme, Pendidikan hemat penulis berperan penting dalam membentuk sikap, karakter, dan pemikiran seseorang (Rawwas, 1988). Pendidikan tidak hanya didapatkan oleh siswa di kelas saja, informasi terkait apapun pada saat ini sangat mudah didapatkan dari sumber lainnya seperti internet dan televisi. Agama memerintahkan seseorang untuk menuntut ilmu setinggi mungkin, bahkan orang yang berilmu mendapatkan keutamaan yang lebih dibandingkan dengan orang bodoh sebagaimana yang diisyaratkan di dalam Al-Quran (An-Naysābūrī, 2002; As-Sa'dī, 2000). Orang tua wajib hukumnya untuk membimbing dan mendidik anak-anak mereka untuk mengenal lebih dekat kepada ajaran agama. Dengan berkembangnya pembelajaran yang tidak hanya tertutup pada tradisional saja, belajar dapat pula dilakukan secara online dengan memanfaatkan konten-konten ilmu pengetahuan yang bersumber dari internet, salah satu yang mendapat penekanan pada riset ini adalah aplikasi Youtube. Serial Nusa dan Rara merupakan konten video yang berisi tentang nilai-nilai ajaran agama meliputi tauhid, ibadah, akhlak, serta muamalah kepada sesame. Studi penelitian pada kesempatan kali ini penulis berupaya untuk mencoba mengeksplorasi dan melakukan kajian analisis terhadap data yang masuk, dimana research question utama difokuskan dalam penggalian informasi opini orang tua terhadap dinamika tayangan Nusa dan Rara. Studi riset yang membahas pendidik anak telah banyak dilakukan oleh para ilmuwan, sengaja penulis ingin mencoba menampilkan realita baru yang memiliki kaitan, namun berimplikasi tidak hanya Pendidikan karakter saja lebih jauh sebagai pelurusan opini yang apabila dibiarkan dapat berbahaya. Studi penelitian terkait pendidikan anak sudah banyak diteliti oleh para sarjana muslim di Indonesia maupun internasional, begitupun terkait riset yang mengangkat tema diskursus Nusa dan Rara ada beberapa yang sudah melakukan, namun sejauh pengamatan penulis, belum ditemukan riset 
khusus yang mengkaji dari sudut pandang lain terkait upaya meluruskan opini radikal yang terkandung dalam serial tersebut akhir-akhir ini. Riset ini sengaja diangkat salah satunya adalah untuk menjawab problematika tersebut, dan tentunya sekaligus menekankan bahwa upaya deradikalisasi justru dapat dibentuk sedini mungkin pada anak Dengan mengkonsumsi tayangan Nusa dan Rara, mengapa? Karena menurut analisis penulis, dengan upaya menayangkan nilai-nilai toleransi, menghargai hak orang lain, menghormati orang lain, saling toleransi, ini dapat menjadi jalan awal dalam rangka membentuk imunitas antiradikalisme pada anak.

Pendidikan anak dalam konteks agama Islam memiliki peran dan kedudukan yang begitu besar. Dalam Al-Quran maupun hadist wacana ini sangat banyak disinggung, sebut saja salah satunya bagaimana kisah fenomenal Luqman Al-Hakim yang diceritakan dalam AlQuran hingga Namanya dijadikan sebagai salah satu nama surat, pesan-pesan mutiaranya terkait pendidik anak begitu banyak dan beragam. Diawali dengan Pendidikan bagaimana memperkenalkan buah hati kepada konsep tauhid hingga bagaimana mengajarkan mereka nilai-nilai karakter islami yang diperintahkan oleh agama. Pada kesempatan kali ini, penulis mencoba sedikit memaparkan perkembangan penelitian yang dilakukan oleh para ulama muslim dalam bingkai tema Pendidikan anak.

Cendekiawan muslim kontemporer Prof. Abdul Karim Bakkar menulis beberapa karya seputar Pendidikan anak diantaranya Musykilat Al-Athfal: Tasykhish wa 'Ilaj Li Ahammi Asyri Musykilat Yu'ani Minha Al-Athfal, Haula At-Tarbiyyah wa At-Ta'lim, Thiflun Yaqra: Afkar Amaliyyah Li Tasyji' Al-Athfal Ala Al-Qiraah, dimana gagasan besarnya adalah strategi-strategi ideal yang dapat diterapkan oleh orang tua dalam rangka mendidik anak menjadi generasi unggul (Bakkar, 2011d, 2011b, 2011c). Selanjutnya, ulama Mesir kontemporer Syeikh Ridha Al-Misri mengembangkan pula teori tarbiyyah al-awlad yang dituangkan dalam karyakaryanya berjudul Masyru' Al-Ibn Al-Bathal, Masyru' Al-Ibn Al-Mahbub dimana esensi dari kitab ini menyumbangkan kontribusi besar terhadap perkembangan teori Pendidikan anak untuk menjadi generasi emas dalam perspektif Islam (Al-Misri, 2010). Terdapat pula penelitian yang menggali secara khusus konsep dan model pendekatan Pendidikan karakter anak yang dilakukan oleh teladan kita Rosulullah Saw diantaranya yaitu buku yang ditulis oleh Syeikh Yusuf Khotir dengan judul Asalib al-Rasul fi al-Dakwah wa al-Tarbiyah, ada pula karya Syeikh Jamal Abdurrahman dengan tema yang sama berjudul Ațäl al-Muslimin Kaifa Rabāhum al-Nabiyyu al-Amīn ('Abd Al-Raḥmān, 2004; al-Suri, Yusuf Khotir Hasan, 1991). Secara umum, Pendidikan karakter terhadap anak mendapatkan respon yang cukup bagus dari kalangan intelektual muslim dimulai pada era klasik hingga kontemporer (Sa'id Ismail Ali, 2000; Said Ismail Ali, 2002; Bakkar, 2011a).

Selanjutnya terkait dengan Pendidikan karakter, beberapa studi riset dilakukan oleh para sarjana muslim Indonesia diantaranya yaitu studi yang dilakukan oleh Fihris dengan judul 'Model Pendidikan Karakter melalui Homestay di SDIT Cahaya Bangsa Semarang' dimana esensi dari riset ini berupaya menggali model Pendidikan karakter melalui konsep homestay (Fihris, 2018). Selanjutnya adapula studi yang dilakukan oleh Dasrun Sajadi dimana beliau berupaya memaparkan konsep teoritis Pendidikan karakter dalam perspektif Islam (Sajadi, 2019). Berikut beberapa judul riset terkait dengan Pendidikan karakter; 1) Implementasi Pendidikan Karakter Melalui Pembelajaran Dalam Mata Pelajaran Di Sekolah Dasar (Malawi, 2016), 2) Pendidikan Karakter Peduli Lingkungan Berbasis Adiwiyata pada Mata Pelajaran Fiqih di MTsN Tambakberas Jombang (Mukani \& Sumarsono, 2017), 3) The Implementation of Role of Kuttab Al-Fatih ( KAF) Philosophy in Islamic Character Education (Mansor et al., 2019), 4) Pendidikan kepribadian anak menurut Abdullah Nashih Ulwan (Imron, 2016), dan lain sebagainya. Secara garis besar, penulis melihat bahwa penelitianpenelitian yang ada terkait Pendidikan karakter mengarah kepada bagaimana anak dapat diarahkan memiliki kepribadian yang positif dengan ruh spirit ajaran agama melalui beragam model pembelajaran dan pendekatan. 
Pada akhir, terkait literature yang membahas kajian khusus Nusa dan Rara, penulis mendapatkan setidaknya ada beberapa yang sudah pernah melakukan, seperti yang dilakukan oleh Siti Ulin Nuha Bersama tim dengan judul Nilai Peduli Sosial pada Film Animasi Nussa dan Rara dimana ia mencoba memaparkan nilai-nilai peduli sosial apa sajakah yang bisa didapatkan dari film animasi ini diantaranya 1) saling menasehati sesame teman, 2) saling tolong menolong, 3) membantu teman yang kesulitan (Nuha et al., 2021). Pada saat bersamaan adapula studi penelitian yang dilakukan oleh Fanny Rizka Afrilia dengan judul Analisis Nilai Karakter Dalam Film Nussa dan Rara Karya Aditya Triantoro, dimana setidaknya ia menemukan ada 18 karakter positif yang ditularkan dari serial ini diantaranya yaitu nilai karakter religius, jujur, toleransi, disiplin, kerja keras, kreatif, mandiri, demokratis, rasa ingin tahu, semangat kebangsaan, cinta tanah air, menghargai prestasi, bersahabat/komunikatif, cinta damai, gemar membaca, peduli lingkungan peduli sosial, dan tanggung jawab (Afrilia, 2020).

\section{METODOLOGI}

Metode yang digunakan pada penelitian ini menggunakan pendekatan kualitatif, dimana pengumpulan data dilakukan melaui teknik observasi, wawancara, dan dokumentasi. Objek penelitian pada riset ini difokuskan kepada 10 informan yang kesemuanya merupakan orang tua yang telah memiliki anak baik laki-laki maupun perempuan. Pada sisi lain, informan diambil berdasarkan seringnya mereka selaku orang tua memberikan tontonan serial animasi Nussa dan Rara kepada anak-anaknya. Pada tataran wawancara, penulis menggunakan strategi wawancara semi terstruktur, dimana pada tahapan persiapan kami menyiapkan instrument yang akan diajukan untuk dijawab, namun demikian pada saat pelaksanaanya terkadang ada pertanyaan yang berkembang yang penulis ajukan sebagai kelengkapan informasi. Analisis pengukuran data menggunakan teori yang dikembangkan oleh Miles dan Hubberman. Adapun terkait waktu penelitian, Riset ini membutuhkan waktu setidaknya dua hingga tiga bulan yang dimulai dari bulan Februari 2021 hingga April 2021. Tabel 1 disajikan instrument pertanyaan yang diajukan kepada para informan.

Tabel 1. Pertanyaan pada informan

\begin{tabular}{|c|c|}
\hline No. & Pertanyaan pada informan \\
\hline 1 & Berapakah usia ibu dan anak ibu? \\
\hline 2 & $\begin{array}{l}\text { Apakah anak ibu sedang mengikuti Pendidikan formal? Bagaimana kegiatan pembelajaran } \\
\text { disana? }\end{array}$ \\
\hline 3 & $\begin{array}{l}\text { Apakah ketika di rumah ibu tetap memberikan edukasi kepada anak? Apakah menggunakan } \\
\text { media? Misalnya serial film }\end{array}$ \\
\hline 4 & Bagaimana respon anak ketika menonton serial film Nussa dan Rara? \\
\hline 5 & $\begin{array}{l}\text { Ada } 5 \text { serial film islami yang cukup popular di Indonesia, diantaranya ada Nussa dan Rara, } \\
\text { Upin dan Ipin, Omar dan Hana, Syamil dan Dodo, serta serial film Adit Sopo Jarwo. Menurut } \\
\text { ibu diantara } 5 \text { serial film tersebut manakah serial yang paling efektif dalam menumbuhkan } \\
\text { nilai nilai islami pada anak? }\end{array}$ \\
\hline 6 & $\begin{array}{l}\text { Bagaimana harapan ibu dalam penerapan nilai nilai islami juga Pendidikan karakter pada } \\
\text { anak itu seperti apa? }\end{array}$ \\
\hline 7 & $\begin{array}{l}\text { Perubahan apa yang terjadi ketika anak ibu sudah menonton serial film islami Nussa dan } \\
\text { Rara? }\end{array}$ \\
\hline 8 & $\begin{array}{l}\text { Apakah Video Nusa dan Rara sangat efektif untuk membentuk prilaku baik menurut islam } \\
\text { terhadap anak? }\end{array}$ \\
\hline 9 & Apa Kendala ibu saat memberikan edukasi kepada anak? \\
\hline 10 & $\begin{array}{l}\text { Apakah dampak negatif yang muncul ketika ibu menggunakan serial film Nussa dan Rara } \\
\text { sebagai media dalam pemberian edukasi kepada anak? }\end{array}$ \\
\hline 11 & $\begin{array}{l}\text { bagaimanakah pendapat ibu terkait adanya opini bahwa nusa rara dianggap menanamkan } \\
\text { karakter radikal, setujukah? Apa alasannya }\end{array}$ \\
\hline
\end{tabular}


Informan yang penulis kumpulkan memiliki karakteristik khusus yang bersinggungan dengan riset penelitian, diantara beberapa karakteristiknya yaitu 1) Orang tua yang rata-rata usia mereka rentang dari 22 tahun hingga 35 tahun, 2) Mereka memiliki anak dengan batasan usia dari 1,5 tahun hingga 11 tahun, 3) Anak mereka Sebagian besar sedang menempuh sekolah formal, dan 4) Domisili informan sangat beragam tidak terfokus dari satu wilayah saja. Pada tabel 2 disajikan demografi informan.

Tabel 2. Demografi Informan

\begin{tabular}{ccccc}
\hline No & Inisial Informan & Gender & Usia & Domisili \\
\hline 1 & CA & P & 30 & Tasikmalaya \\
2 & IR & P & 25 & Tasikmalaya \\
3 & YR & P & 29 & Subang \\
4 & NA & P & 22 & Kalimantan Tengah \\
5 & N & P & 38 & Bandung \\
6 & S & P & 26 & Laswi \\
7 & SM & P & 30 & Garut \\
8 & KN & P & 35 & Cirebon \\
9 & DW & P & 27 & Cirebon \\
10 & PA & P & 39 & Bandung \\
\hline
\end{tabular}

\section{HASIL DAN PEMBAHASAN}

Berdasarkan penelitian yang telah dilaksanakan oleh peneliti dengan menggunakan teknik wawancara terhadap sepuluh orang tua yang memiliki anak berusia 3-6 tahun maka hasil penelitian menunjukkan data-data sebagaimana disajikan pada tabel 3 .

Tabel 3. Hasil wawancara pada informan

\begin{tabular}{|c|c|}
\hline No. & Hasil Wawancara \\
\hline 1 & Rata-rata usia anak dini berusia 1,5 tahun - 11 tahun \& usia orang tuan berusia 22thn- 35thn. \\
\hline 2 & $\begin{array}{l}\text { Sebagian besar anak sedang mengikuti kegitan formal disekolah dan ada juga yang belum } \\
\text { mengikuti kegiatan sekolah formal }\end{array}$ \\
\hline 3 & $\begin{array}{l}\text { Sebagian besar orangtua banyak memeberikan edukasi dirumah dengan serial film kartun yang } \\
\text { mendidik }\end{array}$ \\
\hline 4 & $\begin{array}{l}\text { Sebagian besar respon anak terhadap serial film nussa dan rara begitu sangat antusias dibuktikan } \\
\text { dengan anak menirukan bebrapa kegitan, seperti berdoa sebulum makan, mengucap salam, dan } \\
\text { menyebutkan nama-nama nabi }\end{array}$ \\
\hline 5 & Dari 10 narasumber 9 memilih nussa dan rara dan 1 narasumber memilih omar dan hanna \\
\hline 6 & Harapan orang tua sebagai narasumber yakni menginginkan agar Pendidikan umum dan \\
\hline & $\begin{array}{l}\text { Pendidikan agama berjalan dengan seimbang, sedangkan berdasarkan tayangan Nussa dan Rara } \\
\text { harapannya adalah dapat mengambil nilai-nilai yang diajarkan dan dapat diterapkan pada } \\
\text { kegiatan sehari-hari seperti terbiasa mengucap salam dan berdoa Ketika akan melakukan seuatu }\end{array}$ \\
\hline 7 & $\begin{array}{l}\text { Perubahan yang yang terjadi kepada anak yaitu kebanyakan anak sudah mulai bisa membaca doa } \\
\text { sebelum makan, membaca doa sebelum tidur, mencium dan mengucapkan salam kepada orang } \\
\text { tua }\end{array}$ \\
\hline 8 & $\begin{array}{l}\text { Para orang tua setuju bahwa serial nussa dan rara sangat efektif memebentuk prilaku baik } \\
\text { menurut islam }\end{array}$ \\
\hline 9 & $\begin{array}{l}\text { Dampak negative dari penggunaan media serial nussa dan rara untuk menumbuhkan karakter } \\
\text { islami Anak adalah anak menjadi kecanduan menonton serial nussa dan rara, secara tidak } \\
\text { langsung mereka kecanduan bermain gadget }\end{array}$ \\
\hline 10 & $\begin{array}{l}\text { Beberapa orangtua mengatakan kendalanya anak menjadi kecanduan memegang gadget, } \\
\text { sehingga sulit dipisahkan dengan gadget }\end{array}$ \\
\hline 11 & $\begin{array}{l}\text { Sebagian orang tua tidak setuju jika serial film nussa dan rara dianggap sebagai serial radikal } \\
\text { karna banyak sekali hal positif yang anak dapatkan ketika menonton serial ini ditambah } \\
\text { visualnya yang menarik sehingga anak mudah memahami nilai-nilai islami yang diungkapkan } \\
\text { dalam serial tersebut }\end{array}$ \\
\hline
\end{tabular}


Dari tabel 3 didapatkan bahwa pendidikan karakter islami pada anak usia dini merupakan pendidikan yang sangat penting dimana pada usianya yang masih belia (golden age) anak diberikan pembelajaran mengenai nilai-nilai islami yang bisa langsung mereka aktualisasikan dengan mudah, pentingnya menanamkan nilai islami tentunya sangat berpengaruh terhadap kepribadian anak dan membentuk moral, etika, dan rasa berbudaya yang baik serta berakhlak mulia serta menumbuhkan kemampuan anak untuk memberikan keputusan baik. pengawasan orang tua Ketika anak menggunakan gadget sebagai media edukasi sangat penting, orang tua harus bisa mendampingi, mengawasi, memberikan penjelasan atas beberapa pertanyaan yang dilontarkan anak Ketika menemukan hal yang baru ia ketahui.

\section{Pembahasan}

Data-data yang didapatkan dari hasil wawancara pada kesempatan kali ini penulis akan mencoba untuk mendisikusikannya serta menganalisis secara interaktif dengan menggunakan berbagai pendekatan teoritis seperti kajian Islamic studies, kajian sosiologi.

\section{Pembentukan Karakter Dalam Serial Nusa dan Rara}

secara umum serial animasi Nussa dan Rara dari hasil pantauan penulis menunjukkan banyak sisi positifnya dari para sisi negative. Peran yang ditampilkan dari sosok Nussa sebagai seorang kakak dan Rara sebagai seorang adik dengan menampilkan pakaian yang sopan, menurut hemat penulis sangat layak untuk ditonton oleh anak-anak usia dini dari usia 2 tahun hingga 7 tahun. Tema-tema yang dibahas pada film tersebut mayoritas membahas tentang kisah-kisah religious yang dibalut dengan values dasar-dasar prinsip ajaran Islam seperti akidah, akhlak, ibadah, serta interaksi sosial. Menurut Syeikh Abdullah Nashih Ulwan dalam karyanya Tarbiyatu Al-Awlad fi Al-Islam menerangkan bahwa termasuk diantara hal-hal yang diajarkan oleh Islam yaitu etika-etika penting seperti bagaimana meminta izin, bagaimana etika menjaga pandangan, bagaimana etika bergaul, bagaimana etika atau adab makan, minum (Ulwan, 1983). Lebih lanjut Syeikh Ulwan menyinggung pula dalam karyanya harus adanya konsep ta'lim yang diterapkan oleh orang tua dalam rumah, dimana konsep ini haruslah dibangun berdasarkan pemahaman yang benar terhadap ajaran Islam. Sejalan dengan pendapat diatas, Prof. Abdul Karim Bakar berpandangan bahwa diantara urgensi tarbiyyah yaitu 1) Mendekatkan manusia untuk benar-benar menjadi manusia, 2) Dengan tarbiyyah berfungsi untuk menanamkan sifat-sifat akhlak yang baik, dan 3) Tarbiyyah berfungsi sebagai upaya mendidik anak-anak agar bisa bersosialisasi dengan masyarakat (Bakkar, 2011b). Jadi pada akhirnya sekali lagi penulis memandang bahwa serial ini sudah sangat layak untuk dikonsumsi oleh anak-anak, dan para orang tua tidak mesti harus resah dengan adanya kekhawatiran yang tidak-tidak terhadap konten tersebut.

\section{Internalisasi Nilai-nilai Religius Dalam Serial Nusa dan Rara}

Internalisasi nilai-nilai religious dari film ini dapat dirasakan mayoritas oleh para orang tua dari para informan yang kami tinjau. Hal ini bisa dilihat dari salah satu penuturan informan PA:

"Tayangan serial Nussa dan Rara menurut ibu sangat bermanfaat salah satunya anakanak setelah melihat tayangan videonya jadi rajin mengaji dan rajin melaksanakan shalat tanpa disuruh meskipun dalam praktiknya masih suka saja ada bolong-bolongnya, tapi itu kan namanya berproses, Namanya juga anak-anak"

Nilai-nilai religious dan spiritual yang terkandung dalam film Nussa dan Rara diantaranya yaitu rajin, giat, sayang terhadap sesame, menghormati orang tua, mengawali aktivitas dengan berdoa, dan yang lain sebagainya. Saat ini, pandemi Covid-19 membawa perubahan besar-besaran dalam segala aspek, salah satu yang terkena imbas yaitu sistem Pendidikan. Pendidikan yang sejatinya biasanya dilaksanakan disekolah secara tatap muka, 
dengan adanya kebijakan dari bapak Menteri Pendidikan, sistem belajar-mengajar dialihkan kepada di rumah. Fenomena ini tentunya menjadi beban tersendiri bagi para orang tua, dimana mereka sudah disibukkan dengan mencari penghasilan untuk menafkahi keluarga. Oleh sebabnya, Pendidikan karakter yang ideal pada suasana seperti ini yaitu anak-anak diberikan tayangan-tayangan positif yang mengandung nilai-nilai ajaran agama salah satunya yaitu film Nussa dan Rara ini. Walaupun demikian, ada pula kekhawatiran yang dicemaskan oleh orang tua salah satunya yaitu efek kecanduan, terkadang anak jadi lupa waktu saking asyiknya menonton. Untuk kasus seperti ini, penulis menyarankan setidaknya orang tua memonitor aktivitas anak serta melakukan perjanjian misalnya "boleh menonton kalau sudah belajar ya nak! Tapi ingat, hanya 1 jam saja yah...!”, strategi seperti ini menurut penulis dapat menjadi satu solusi mengatasi efek kecanduan.

Mengatasi kecanduan dan mengalihkan sifat negative tersebut kepada bagaimana mereka didorong untuk bersemangat dalam belajar, mungkin bisa mencoba tips dan strategi yang diberikan oleh Prof. Abdul Karim Bakkar dalam karyanya Musykilat Al-Athfal: Tasykhish wa 'Ilaj Li Ahammi Asyri Musykilat Yu'ani Minha Al-Athfal (problematika yang sering terjadi pada anak) dimana salah satu upayanya yaitu mengulang-ngulang nasehat-nasehat positif dengan dibumbui kisah-kisah inspiratif kepada anak secara simultan, hal ini dimaksudkan agar anak dapat mereka point nasehat tersebut dan mengarahkan perilaku anak agar selaras dengannya (Bakkar, 2011c).

\section{Membangun Imunitas Anti-Radikalisme Melalui Tayangan Nusa dan Rara}

Salah satu point penting yang hendak ditekankan oleh penulis pada kesempatan kali ini yaitu untuk menjawab pandangan yang keliru yang sengaja dinisbatkan kepada film ini dengan tuduhan konten film mengandung unsur radikal. Hasil riset justru bertolak belakang dengan opini dan tuduhan tersebut dimana mayoritas para informan orang tua justru melihat bahwa film ini tidak ada sama sekali unsur radikal, sebagaimana yang diopinikan. Menurut pengamatan penulis, tayangan Nussa dan Rara jauh sekali dari konten berbau benih-benih paham radikalisme. Sejauh pengamatan penulis dalam melihat tayangan-tayangan videonya, belum pernah melihat bagaimana aksi-aksi bom, aksi-aksi brutal, aksi-aksi anarkis dimunculkan dalam videonya. Bahkan lebih jauh, tayangan film ini dapat berperan pula menjadi melahirkan sistem imunitas dari paham-paham radikalisme yang kontradiktif dengan ajaran islam pada jiwa anak. Mengapa? Karena anak sudah jauh-jauh hari diajarkan dalam konten film tersebut kepada bagaimana menebarkan kasih sayang, bagaimana menebarkan sikap toleransi terhadap sesame, bagaimana menebarkan sikap menghormati kepada yang lain. Sistem imunitas ini menurut penulis sangat dimungkinkan untuk terjadi, karena sekali lagi apabila kita menelaah hadist-hadist terkait dengan konsep lingkungan yang berpengaruh terhadap anak, maka jika dikembangkan lebih jauh bisa jadi lingkungan ini bukan hanya bersifat materi saja seperti teman, orang tua, maupun guru, namun maksud dari lingkungan ini dapat dimaknai pula bagaimana informasi-informasi yang dikonsumsi oleh anak. Nah oleh sebabnya, dengan menanamkan nilai-nilai toleran serta menjauhi sikap ekstrem dan intoleran yang diperlihatkan oleh Nussa dan Rara, maka sekali lagi sangat dimungkinkan kehadirannya dapat melahirkan imunitas paham radikal pada anak sedini mungkin.

Sebagaimana beberapa teori terkait wacana radikalisme yang telah dibahas pada sebelumnya, gerakan ekstrem yang dilakukan oleh oknum-oknum tertentu dengan menanamkan ideologi radikalisme pada anak sejatinya secara umum salah satu objek serangan adalah wilayah pendidikan, hal ini sebagaimana riset yang dikaji oleh Suyanto. Oleh sebabnya, deradikalisasi ideologi radikalisme melalui internalisasi nilai-nilai toleransi pada anak merupakan hal yang fundamental untuk memperkokoh pemahaman anak serta membangun imunitas yang dapat menjadi sistem kekebalan awal bagi paham-paham kontradiktif dengan ajaran agama Islam. 


\section{KESIMPULAN}

Keberadaan film serial Nussa dan Rara dalam bentuk audio visual yang popular di Youtube merupakan salah satu potensi besar yang dapat dimanfaatkan oleh para orang tua dalam rangka menanamkan nilai-nilai karakter islami sedini mungkin. Disamping itu, upaya untuk tetap memonitor aktivitas anak selama berselancar di internet maupun youtube tetaplah harus dilakukan pula, hal ini setidaknya meminimalisir resiko anak membuka konten video yang tidak layak untuk dilihat. Pada sisi lain, penulis ingin sedikit memberikan penekanan pada kesimpulan bahwa anggapan video serial ini berbau konten paham-paham radikal tidaklah benar dan valid, oleh sebabnya anggapan ini haruslah dikaji lebih lanjut dalam studi-studi di masa yang akan datang. Fakta di lapangan menunjukkan sebaliknya, Film Nussa dan Rara justru berperan besar sebagai media dakwah mengajarkan anak-anak mengenal agama Islam lebih jauh. Anak diperkenalkan dengan konsep beriman kepada Allah Swt, meneladani para Nabi dan Rasul dalam aktivitas kegiatannya, serta mengajarkan tentang bagaimana mereka harus memiliki jiwa sosial tatkala di masa yang akan datang mereka hidup berdampingan dengan masyarakat.

\section{UCAPAN TERIMA KASIH}

Terima kasih disampaikan kepada Prodi Departemen Pendidikan Umum dan Ilmu Pendidikan Agama Islam Fakultas Pendidikan Ilmu Pengetahuan Sosial (FPIPS) Universitas Pendidikan Indonesia yang telah mendukung riset penelitian ini, dan juga saya sampaikan terima kasih kepada pihak pengelola Jurnal Obsesi atas kesempatannya untuk mempublikasikan riset ilmiah ini, semoga bisa riset ini dapat menjadi kebaikan bagi kita Bersama, Amin.

\section{DAFTAR PUSTAKA}

Afrilia, F. R. (2020). Analisis Nilai Karakter Dalam Film Nussa dan Rara Karya Aditya Triantoro. Caruban: Jurnal Ilmiah Ilmu Pendidikan Dasar, 3(2), 130. https://doi.org/10.33603/cjiipd.v3i2.3065

Ali, Sa'id Ismail. (2000). Al-Qur'an Al-Karim Ru'yatu Tarbawiyyah.pdf.

Ali, Said Ismail. (2002). Ushul Al-Fiqh At-Tarbawi Al-Islami: As-Sunnah Al-Nabawiyyah Ru'yah Tarbawiyyah. Kairo: Dar Al-Fikr Al-Arabi.

Al-Mālikī, M. bin A. (1993). Mafāhīm Yajib An Tushahhah. Kairo: Dār Jawāmi' Al-Kalim.

Al-Mālikī, M. bin A. (2003). Al-Ghuluwwu wa Atsaruhu fī Al-Irhāb wa Ifsād Al-Mujtama'. Makkah: Al-Hiwār Al-Wathanī.

Al-Mālikī, M. bin A. (2004). At-Tahdzīr min Al-Mujāzafati bi At-Takfīr. Kairo: Dār Jawāmi' AlKalim.

Al-Misri, R. (2010). Masyru' Al-Ibn Al-Bathal. Kairo: Dar Al-Fadhilah.

Al-Qardhawi, Y. (1990). Dzāhiratu Al-Guluwwu Fī At-Takfīr. Cairo: Maktabah Wahbah.

Al-Qardhawi, Y. (1993). Syarī'atu Al-Islāmiyyah Shālihatun Lil Tathbīq Fī Kulli Zamān Wa Makān. Cairo: Dar As-Shahwah Lil Nasyr Wa Tauji'.

Al-Qardhawi, Y. (2008). Kalimat fi Al-Wasatiyyah Al-Islamiyyah Wa Ma'alimuha. Cairo: Dar AsSyuruq.

al-Suri, Yusuf Khotir Hasan, Y. (1991). Asalib al-Rasul fi al-Dakwah wa al-Tarbiyah (p. 85).

An-Naysābūrī, A. B. M. bin I. bin M. (2002). Kitāb Tafsīr Al-Qurān. Madinah: Dar Al-Ma'atsir.

As-Sa'dī, A. bin N. bin A. (2000). Taysīr Al-Karīm Ar-Rahmān fī Tafsīr Kalām Al-Mannān. Beirut: Muassah Ar-Risalah.

Bakkar, A. K. (2011a). Al-Tawasul Al-Usra: Kaifa Nuhmiya Usrana min At-Tafakkuk. Riyadh: Maktabah Al-Malik Fahd Al-Wathaniyyah.

Bakkar, A. K. (2011b). Haula At-Tarbiyyah wa At-Ta'lim. Beirut: Dar Al-Kalam.

Bakkar, A. K. (2011c). Musykilat Al-Athfal: Tasykhish wa 'Ilaj Li Ahammi Asyri Musykilat Yu'ani Minha Al-Athfal. Riyadh: Maktabah Al-Malik Fahd Al-Wathaniyyah.

Bakkar, A. K. (2011d). Thiflun Yaqra: Afkar Amaliyyah Li Tasyji' Al-Athfal Ala Al-Qiraah. Riyadh: Maktabah Al-Malik Fahd Al-Wathaniyyah. 
Fihris, F. (2018). Model Pendidikan Karakter melalui Homestay di SDIT Cahaya Bangsa Semarang. Edukasia Islamika, 3(2), 131. https:// doi.org/10.28918/jei.v3i2.1684

Imron, A. (2016). Pendidikan kepribadian anak menurut Abdullah Nashih Ulwan. Edukasia Islamika, 1(1), 89-118.

Kurzman, C. (2019). The Missing Martyrs: Why Are There So Few Muslim Terrorists? New York: Oxford University Press. https:// doi.org/10.1093/oso/9780190907976.001.0001

Malawi, I. (2016). Implementasi Pendidikan Karakter Melalui Pembelajaran Dalam Mata Pelajaran Di Sekolah Dasar. Premiere Educandum: Jurnal Pendidikan Dasar Dan Pembelajaran, 3(01), 1-12. https://doi.org/10.25273/pe.v3i01.55

Mansor, R., Malim, T., Nichiappan, S., \& Malim, T. (2019). The Implementation of Role of Kuttab Al-Fatih ( KAF ) Philosophy in Islamic Character Education. Nadwa Jurnal Pendidikan Islam, 13(2), 235-250. https:// doi.org/10.21580/nw.2019.13.2.5184

Mukani, M., \& Sumarsono, T. (2017). Pendidikan Karakter Peduli Lingkungan Berbasis Adiwiyata pada Mata Pelajaran Fiqih di MTsN Tambakberas Jombang. Jurnal Pendidikan Agama Islam (Journal of Islamic Education Studies), 5(2), 181. https://doi.org/10.15642/jpai.2017.5.2.181-200

Nuha, S. U., Ismaya, E. A., \& Fardani, M. A. (2021). Nilai Peduli Sosial pada Film Animasi Nussa dan Rara. Jurnal Riset Pendidikan Dasar, 4(1), 17-23.

Rawwas, M. (1988). Dirasah Tahliliyyah Li Syahshiyati Ar-Rasul Muhammad (pp. 1-303). Dar AnNafais.

Sajadi, D. (2019). Pendidikan Karakter Dalam Perspektif Islam. Tahdzib Al-Akhlaq: Jurnal Pendidikan Islam, 2(2), 16-34. https://doi.org/10.34005/tahdzib.v2i2.510

Saunders, C. (2012). Reformism and radicalism in the Climate Camp in Britain: Benign coexistence, tensions and prospects for bridging. Environmental Politics, 21(5), 829-846. https:// doi.org/10.1080/09644016.2012.692937

Schofield, P. (2004). Jeremy Bentham, the French Revolution and political radicalism. History of European $\quad$ Ideas, 30(4 381-401. https://doi.org/10.1016/j.histeuroideas.2003.11.019

Soliman, A., Bellaj, T., \& Khelifa, M. (2016). An integrative psychological model for radicalism: Evidence from structural equation modeling. Personality and Individual Differences, 95, 127-133. https://doi.org/10.1016/j.paid.2016.02.039

Suyanto, B., Sirry, M., \& Sugihartati, R. (2019). Pseudo-Radicalism and the De-Radicalization of Educated Youth in Indonesia. Studies in Conflict and Terrorism, 0(0), 1-20. https://doi.org/10.1080/1057610X.2019.1654726

Turner, J. (2020). Manufacturing the Jihad in Europe: The Islamic State's Strategy. International Spectator, 55(1), 112-125. https:// doi.org/10.1080/03932729.2020.1712136

Ulwan, A. N. (1983). Tarbiyyah Al-Aulad Fil Islam (p. Jilid 1).

Varouxakis, G. (2004). French radicalism through the eyes of John Stuart Mill. History of European Ideas, 30(4 SPEC.ISS.), 433-461. https:// doi.org/10.1016/j.histeuroideas.2003.11.018

Yang, D. L., Xu, H., \& Tao, R. (2014). A Tragedy of the Nomenklatura? Career incentives, political loyalty and political radicalism during China's Great Leap Forward. Journal of Contemporary China, 23(89), 864-883. https://doi.org/10.1080/13603116.2014.882560

Yusof, K., Herman, I., \& Nasir, B. M. (2010). Islamic radicalism in Malaysia: Gender perspective. Procedia - Social and Behavioral Sciences, 5, 2119-2125. https://doi.org/10.1016/j.sbspro.2010.07.424

Yusoff, K. (2010). Islamic radicalism in Malaysia: An overview. Procedia - Social and Behavioral Sciences, 5, 2326-2331. https://doi.org/10.1016/j.sbspro.2010.07.458

Zamboni, G., Gozzi, M., Krueger, F., Duhamel, J. R., Sirigu, A., \& Grafman, J. (2009). Individualism, conservatism, and radicalism as criteria for processing political beliefs: a parametric fMRI study. Social Neuroscience, 4(5), 367-383. https:// doi.org/10.1080/17470910902860308 